\title{
Vaccination against GnRH: pros and cons Stig Einarsson*
}

Address: Department of Clinical Sciences, Faculty of Veterinary Medicine and Animal Science, Swedish University of Agricultural Sciences (SLU), Centre for Reproductive Biology in Uppsala, Box 7054, SE-750 07 Uppsala, Sweden

* Corresponding author

from Prevention of Boar Taint in Pig Production: The 19th Symposium of the Nordic Committee for Veterinary Scientific Cooperation Gardermoen, Norway. 2I-22 November 2005

Published: 7 August 2006

Acta Veterinaria Scandinavica 2006, 48(SuppI I):SI0 doi:I0.II86/I75I-0I47-48-SI-SIO

Cㄱ 2006 Einarsson.; licensee BioMed Central Ltd.

\section{Introduction}

The meat of intact male pigs may exhibit odours, known as boar taint. The compounds responsible for boar taint include skatole (3-methylindole), a product of tryptophan breakdown in the gut and testicular 16-androstene steroids, mainly androstenone (5 $\alpha$-androst-16-en-3one), and these compounds are accumulated in fat tissue. Active immunization against androstenone has been tried, but the effects on fat androstenone level and boar odour intensity were insufficient [1]. Other methods which have been tried in several species are pharmacological manipulations of gonadotropin releasing hormone (GnRH) activity, such as GnRH antagonists or large doses of agonists to block the activity of GnRH and thereby "switch-off" the reproductive endocrine systems. More successful method of inhibiting sexual development in young boars and boar taint is immunization against GnRH. In most experimental studies using GnRH vaccines during the eighties and early nineties several injections were required and/or severe local reactions at the site of injection were obtained due to the adjuvans (e.g. Falvo et al. [2]; Hagen et al. [3]; Bonneau et al. [4]. In this paper GnRH vaccine developed during late nineties and early twenties is presented and discussed.

\section{Hormonal background - mechanism of a GnRH vaccine}

Androstenone is produced by the Leydig cells of the testis. The production of androstenone and other testicular steroids is controlled by the neuroendocrine system, particularly by LH. LH-secretion is mainly regulated by GnRH produced by the hypothalamus. LH binds to the receptors on the surface of the Leydig cells, resulting in the induction of steroidogenic enzymes and increased levels of tes- ticular steroids. The biosynthesis of androstenone is low in young male pigs, but increases at puberty in parallel with other testicular steroids.

Measurements of GnRH and LH (rat, ram) have shown that $\mathrm{GnRH}$ and $\mathrm{LH}$ are secreted in a pulsatile manner, with a high degree of concordance between GnRH and LH pulses. The testes exert negative feedback actions on the hypothalamo-pituitary unit. The predominant site at which testicular steroids act to regulate the secretion of LH seems to be within the central nervous system, not at the level of the pituitary gland [5]. How testosterone and/or its primary metabolites act within the brain to suppress the synthesis and/or secretion of GnRH remains essentially unknown.

GnRH, a small peptide (decapeptide) is released from the hypothalamus into the hypophysial portal blood. It is produced in cell bodies of hypothalamic neurons and is transported by axonal flow to the terminal buttons, which synapse on the vessels of the primary capillary plexus within the median eminence [6-8]. Exitation of the GnRH neurons causes release of stored peptide from the secretory granules into the extracellular space, with eventual diffusion into the capillary blood. This blood then travels via the hypophysial portal system to the sinusoidal (seconday) capillary plexus within the adenohypophysis, where a portion of the GnRH leaves the capillaries and thereby becomes available for binding to its pituitary target cells, the gonadotropes. The short distance (and time) that the GnRH travels in these vessels is where (when) it is vulnerable to be attacked by antibodies. If enough specific antibodies are present in the circulating blood entering the median eminence, then virtually all the GnRH 
secreted into the primary plexus is tightly bound by antibody. Binding to antibody "neutralizes" the GnRH either by preventing it from diffusing through the capillary walls (due to the complex) or by masking the receptor binding site on the GnRH molecule itself.

GnRH is too small to be immunogenic. Therefore, the GnRH molecule must be conjugated to a carrier protein along with the use of an adjuvant. GnRH vaccination involves the injection of GnRH (or a modified form of the hormone, an analogue) conjugated to a foreign protein, and combined with an adjuvant, to induce anti-GnRH antibody formation.

Two major factors to be considered in the development of vaccines against $\mathrm{GnRH}$ for commercial use in farm animal species are the adjuvant used, and the number of immunizations needed for effective immunocastration.

\section{Vaccination of young boars with a GnRH vaccine (Improvac ${ }^{\circledR}$ )}

Improvac contains a modified form of GnRH (200 ug GnRH-protein conjugate $/ \mathrm{ml}$ ) in an aqueous adjuvant system. The analogue of GnRH, used in this vaccine has no hormonal effect or chemical activity [9]. The results from three vaccination studies are briefly presented here: I, Dunshea et al. [9] (Australia); II, Jaros et al. [10] (Switzerland); III, Cronin et al. [11] (Australia). In these studies the male pigs were vaccinated twice. The second dose, which is expected to elicit an immune reaction with high antibody titres against GnRH should be given no later than 4 to 5 weeks prior to slaughter, to allow any boar taint substances already present to be metabolised/eliminated.

\section{Experimental protocol}

I: Three hundred male (200 boars and 100 barrows) pigs were used in a $2 \times 3$ factorially arranged experiment at a commercial pig enterprise. The respective factors were sex group (castrated between 1 and 2 weeks of age; vaccinated with Improvac; placebo vaccinated) and slaughter age (23 or 26 weeks). They were allocated within sex to pens of 10 according to treatment. Pigs to be slaughtered at 23 weeks of age were vaccinated at 15 and 19 weeks of age, whereas pigs slaughtered at 26 weeks of age were vaccinated at 18 and 22 weeks of age. Boars were vaccinated under a double-blind study protocol.

The injection sites of each pig were inspected by palpation at weekly intervals for 4 weeks. At slaughter "fighting lesions" around the neck and shoulders were recorded.

II: A total of 533 male pigs from two different breeding farms were used. After parturition, male piglets of each litter were randomly assigned to two groups, with 270 ani- mals for immunocastration and 263 animals for surgical castration (controls) within the first 14 days of life. After weaning at $25 \mathrm{~kg}$ of weight, all littermates (intact males and barrows) were transported to two different farms. In the new farms pigs were kept in pen-groups of 10 animals, independent of their sex. Pigs were vaccinated twice at an interval of at least 4 to 5 weeks with the second dose being given 4 to 6 weeks prior to slaughter. The animals were slaughtered at 100-110 kg bodyweight.

III: The behaviour of group-housed, male finisher pigs was studied. Twelve groups of 15 male pigs were formed at 14 weeks of age ( $47 \mathrm{~kg}$ mean live weight). Pig behaviour was compared among groups of entire males, immunocastrated males (treated with Improvac at 14 and 18 weeks of age) and surgically castrated males (castrated at 14 days old). A 24-hour time-lapse video record was made for each pen of pigs at 17 and 21 weeks of age.

\section{Results}

\section{Antibody response and testes}

In pigs treated with two doses of Improvac, an immune response against GnRH was detectable in all animals (I). The response was lower in some pigs but never below a titer of 100. The primary dose of the GnRH vaccine seemed to have had no physiological effect on testicular function as assessed by the testicular size and serum testosterone concentrations at the time of the secondary dose. However, within 2 weeks of the second vaccination, testicular growth and secretion of testosterone were suppressed. At slaughter, testes weight and bulbo-urethral gland weight were approximately $50 \%$ lighter in the vaccinated pigs (I, II).

\section{Androstenone and skatole in subcutaneous fat (I, II)}

Placebo-treated boars had fat androstenone levels almost eight times greater than those of the Improvac-treated boars, which were not different from the barrows. Placebo-vaccinated boars had fat skatole levels almost twice as high as those of the Improvac-treated boars, which were not different from the barrows.

\section{Site reactions and carcass lesions (I)}

The majority of vaccinated boars showed no reaction following subcutaneous treatment (no difference between Improvac or placebo vaccination). Many of the pigs that exhibited site reactions did so at only one time point. At slaughter there were no visible site reactions in any pigs, whereas in 12 out of 192 vaccinated pigs there was a reaction that could be detected by palpation. "Fighting lesions" around the head and shoulders were recorded in 30 pigs, 26 of which belonged to the placebo group and 6 were Improvac-treated boars. They probably arose due to fighting during transport to the abattoir and/or in the 
overnight lairage at the abbattoir prior to slaughter. No fighting scars were found among the barrows.

\section{Efficiency of lean meat production}

There were indications that the per cent of lean meat was higher in Improvac vaccinated than in surgically castrated animals.

\section{Behaviour (III)}

The Improvac vaccinated pigs spent less time engaged in socio-sexual behaviour than intact male pigs after the secondary vaccination (recorded at 21 weeks of age); at this age there was no difference in socio-sexual or feeding behaviour between the Improvac vaccinated and the surgically castrated male pigs.

\section{Advantages and disadvantages with Improvac vaccination \\ Advantages}

- Avoid surgical procedure of male piglets, which is associated with some pain and stress even when performed under local or general anaesthesia.

- Two vaccinations with 4 to 6 weeks interval, the last administered approximately 4 weeks before slaughter is effective in reducing the androstenone and skatole concentrations in fat to levels similar to those observed in pigs surgically castrated before 2 weeks of age. Only 3 per cent of the Improvac-treated boars and none of the barrows had fat androstenone concentrations of $0.5-1.0 \mu \mathrm{g} / \mathrm{g}$ fat [9]. The European Union accept a threshold level of $0.5 \mu \mathrm{g}$ androstenone/g fat. In another study [10] only 2 out of 270 immunocastrated animals had androstenone concentrations above $0.5 \mu \mathrm{g} / \mathrm{g}$ fat $(1.0$ and $1.4 \mu \mathrm{g} / \mathrm{g}$ fat respectively). Those 2 animals had also high testicular weights (>500 g). The reason for this is not clear, but may most likely be due to lack of immunological response; the antibody titer varies between individuals. Corresponding results were obtained for skatole concentrations. The few GnRH vaccinated pigs that had intermediate concentrations of either androstenone or skatole at slaughter did not have significant levels of both compounds.

- The aqueous proprietary adjuvant system of Improvac caused very little irritation at the injection site of the vaccinated pigs.

- A decrease in aggressive and sexual behaviour was observed after the secondary Improvac vaccination, as a consequence of suppression of testicular function. The decrease in "fighting lesions" exhibited after transport and lairage in the vaccinated boars is also ascribed to the reduced aggressive behaviour in these animals.
- The male pig is left intact for most of its production life, thus gaining the natural growth advantages of boars.

\section{Disadvantages}

- For effective immunization against androstenone (development of anti-GnRH antibodies) two vaccinations 4 weeks apart are required, the seconday given 4 to 5 weeks prior to slaughter. It is not very easy to vaccinate group-penned pigs of that weight.

- To avoid accidental self injection by operators, this product should be administered using a vaccinator which employs a needle safety shield. According to the recommendations given by the vaccine producer, "the operators should be trained in procedures for safe use of this material. Not to be used by women of child bearing age".

- Due to individual variation in immunological response to Improvac, a few vaccinated male pigs will still have too high concentrations of andostenone in the fat. On the other hand, it also occurs that cryptorchids are sent to slaughter as barrows. Cryptorchids have taint of the same magnitude as entire males.

\section{Recommendations}

Further clinical tests under careful supervision are needed before considering the introduction of this method in Scandinavian countries. Special attention should be paid to the communication with consumers. It is very important with correct information regarding both advantages and disadvantages of Improvac to consumers and farmers.

\section{References}

I. Williamson ED, Patterson RLS, Buxton ER, Mitchell KG, Partridge IG, Walker $\mathrm{N}$ : Immunization against $5 \alpha$-androstenone in boars. Livest Prod Sci 1985, I 2:25 I-264.

2. Falvo RE, Chandrashekar V, Arthur RD, Kuenstler AR, Hasson T, Awoniyi C, Schanbacher BD: Effect of active immunization against LHRH or LH in boars: reproductive consequences and performance traits. J Anim Sci 1986, 63:986-994.

3. Hagen $G$, Andresen $\varnothing$, Blichfeldt T, Berg KA: Effects of immunization of young boars against gonadotropin releasing hormone. Proceedings from the IIth Int Congr Anim Reprod \& Al Dublin 1988, I:.

4. Bonneau M, Dufour R, Chouvet G, Roulet C, Meadus W, Squires E]: The effects of immunization against luteinizing hormonereleasing hormone on performance, sexual development, and levels of boar taint-related compounds in intact male pigs. J Anim Sci 1994, 72: 14-20.

5. Tilbrook AJ, Clarke IJ: Negative feedback regulation of the secretion and actions of gonadotropin-releasing hormone in males. Biol Reprod 200I, 64:735-742.

6. Thompson DL Jr: Immunization against $\mathbf{G n R H}$ in male species (comparative aspects). Anim Reprod Sci 2000, 60-61:459-469.

7. Clarke IJ, Pompolo S: Synthesis and secretion of GnRH. Anim Reprod Sci 2005, 88:29-55.

8. Millar RP: GnRH and GnRH receptors. Anim Reprod Sci 2005, 88:5-28.

9. Dunshea FR, Colantoni C, Howard K, McCauley I, Jackson P, Long KA, Lopaticki S, Nugent EA, Simons JA, Walker J, Hennessy DP: Vaccination of boars with a GnRH vaccine (Improvac) eliminates boar taint and increases growth performance. J Anim Sci 200I, 79:2524-2535. 
10. Jaros P, Bürgi E, Stärk KDC, Claus R, Hennessy D, Thun R: Effect of active immunization against $\mathrm{GnRH}$ on androstenone concentration, growth performance and carcass quality in intact male pigs. Livest Prod Sci 2005, 92:3I-38.

II. Cronin GM, Dunshea FR, Butler KL, McCauley I, Barnett JL, Hemsworth $P$ : The effects of immuno- and surgical-castration on the behaviour and consequently growth of group-housed, male finisher pigs. Appl Anim Behav Sci 2003, 8 I : I I I-I 26.

Publish with Bio Med Central and every scientist can read your work free of charge

"BioMed Central will be the most significant development for disseminating the results of biomedical research in our lifetime. " Sir Paul Nurse, Cancer Research UK

Your research papers will be:

- available free of charge to the entire biomedical community

- peer reviewed and published immediately upon acceptance

- cited in PubMed and archived on PubMed Central

- yours - you keep the copyright

Submit your manuscript here:

http://www.biomedcentral.com/info/publishing_adv.asp 